\title{
Optimal paramerers for curing graphite/epoxy composite laminates
}

\author{
T. Y. Kam, F. M. Lai and H. F. Sher
}

Department of Mechanical Engineering, National Chiao Tung University, Hsin Chu, 30050 Taiwan, R. O. C.*

The optimal curing parameters of a cure cycle for achieving maximum mechanical properties of Gr/ep composite laminates are determined via a multi-level optimization approach. Laminated composite specimens cured under various pressures, temperatures and times are tested with an Instron testing machine. Test results are then used in the proposed multi-level optimization method to determine the optimal curing parameters. The effects of the curing parameters on the mechanical properties of the laminates are studied and discussed. It was found that a cure cycle with two pressure-temperature-time steps can yield composite laminates with comparatively good material properties.

\section{INTRODUCTION}

Laminated composite materials have become an important engineering material in the mechanical, aerospace, marine and automotive industries. The structures or components made with laminated composite materials, in general, require good quality and high reliability. Therefore, the manufacture of good composite laminates has become a subject of active research $[1,2]$. In particular, the curing process of composite laminates has drawn close attention [3-6]. Generally prepreg reinforced plastic parts can be cured in a cure cycle to achieve the desired configuration and structural strength. The specific cure cycle for a part is based upon the resin system, thickness of the part, the type of mold material, and the thickness of the actual mold. The determination of the best cure cycle within the constraints of short processing time, good properties, and low thermal stresses then becomes an important subject of research.

This paper presents a multi-level optimization method for the determination of optimal curing parameters of a cure cycle. Since the multi-level optimization approach has been successfully used in the design of laminated composite structures $[7,8]$, it is worthy to extend the idea to the determination of the best cure cycle. Herein, the proposed method will be used to investigate the optimal curing pressures, temperatures and times of a cure cycle for Graphite/epoxy (Q-1115) composite laminates. The effects of curing parameters on the material properties of the laminates are studied and discussed.

\section{OPTIMIZATION THEORY}

The optimal curing parameters, namely, curing pressures, temperatures and times for maximizing the material properties of composite laminates will be determined via an optimization approach. Let $F(\underline{p}, \underline{\theta}, \underline{t})$ denote a material property function which depends on the vectors of curing pressures $\underline{P}$, temperatures $\underline{\theta}$ and times $\underline{t}$. It is noted that the dimensions of $\underline{P}, \underline{\theta}$ and $\underline{t}$ depend on the number of pressure-temperature-time $(\underline{p}-\underline{\theta}-\underline{t})$ steps adopted in the cure cycle. The objective of the present study is to find $(\underline{p}, \underline{\theta}, \underline{t})$ for maximizing $F$. In mathematical form, the above optimization

*This research was supported by the National Science Council of Republic of China under Grant No. NSC 82-0401-E-009-156. 
problem can be stated as

$$
\begin{array}{ll}
\text { maximize } & F(\underline{p}, \underline{\theta}, \underline{t}) \\
\text { subject to } & \underline{p}, \underline{\theta}, \underline{t}>\underline{0}
\end{array}
$$

Since the objective function implicitly depends on the curing parameters, the direct solution of the above equation is intractable if not impossible. Herein, a multi-level optimization technique is developed to estimate the optimal curing parameters. In the present multi-level optimization approach, the original problem is divided into a set of sub-problems. In the first level of optimization, the conditional optimal curing pressures are determined by solving the following optimization problem

$$
\begin{gathered}
\operatorname{maximize} \quad F\left(p_{i} \mid \underline{\theta}, \underline{t} ; p_{1} \cdot, p_{i-1}, p_{i+1}, \cdots p_{m}\right) \\
\text { with respect to } P_{i} \\
\text { subject to } \quad p_{i}>0 \quad, i=1, \cdots, m
\end{gathered}
$$

in which $p_{i}$ is the design variable to be detcrmined under the condition that the values of the other design variables are unaltered, and $m$ is the number of $\underline{p}-\underline{\theta}-\underline{t}$ steps in the cure cycle. The same optimal design process will be conducted for the other pressure variables. The conditional optimal curing pressure $\tilde{p}_{i}$ is obtained by solving the following one-dimensional optimization problem [9]

$$
\operatorname{maximize} \quad F \cong a_{0}+a_{1} p_{i}+a_{2} p_{i}^{2}+a_{3} p_{i}^{3}
$$

where $a_{j}(j=0, \cdots, 3)$ are constants determined from the observed values of $F$ and $p_{i}$.

In a similar approach, the second and third levels of optimization can be expressed, respectively, as

$$
\begin{array}{ll}
\text { maximize } & F\left(\theta_{i} \mid \underline{p} ; \underline{t} ; \theta_{1} \cdots, \theta_{i-1}, \theta_{i+1}, \cdots \theta_{m}\right) \\
& \text { with respect to } \theta_{i} \\
\text { subject to } & \theta_{i}>0, i=1, \cdots, m
\end{array}
$$

and

$$
\begin{array}{cl}
\text { maximize } & F\left(t_{i} \mid \underline{p} ; \underline{\theta}, t_{1} \cdot, t_{i-1}, t_{i+1}, \cdots t_{m}\right) \\
& \text { with respect to } t_{i} \\
\text { subject to } & t_{i}>0, i=1, \cdots, m
\end{array}
$$

Optimal solution is obtained by iterating solutions of the sub-problems among the three different levels of optimization. A schematic description of the proposed multi-level approach is given in Fig. I. In general, $m$ is chosen as 1 (one $p-\theta-t$ step) or 2 (two $p-\theta-t$ steps) for practical applications.

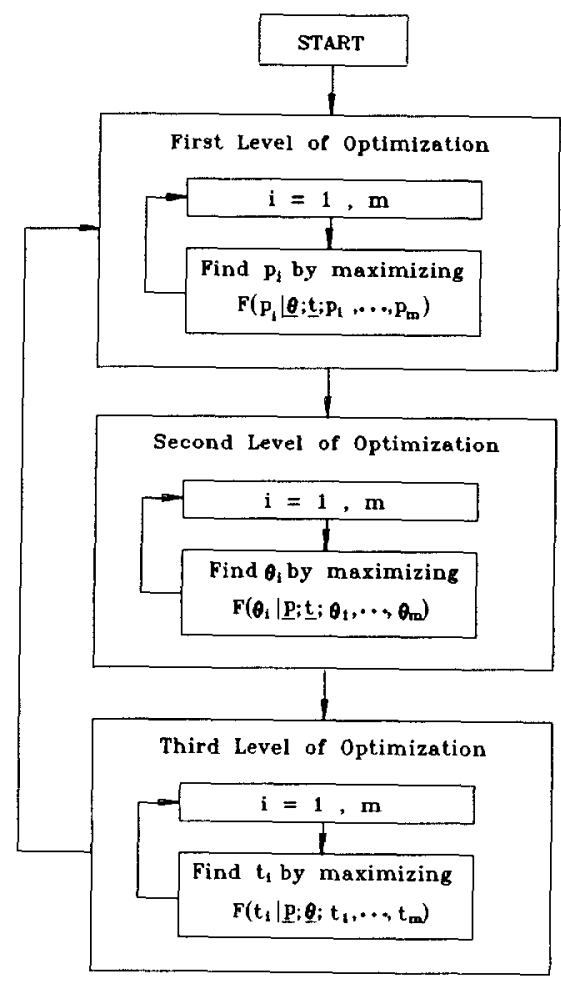

Fig. 1 A schematic description of multi-level optimization method 


\section{EXPERIMENTAL PROCEDURE}

Graphite/epoxy (Q-1115) prepreg tape supplied by Toho Co., Japan, is used to make the composite laminated specimens for mechanical property testing of the laminates. The essential steps in the manufacturing of the laminates are lay-up of plies, construction of a bleeder system, vacuum bagging, and curing under pressure and elevated temperature [1]. In laying up the plies, squeegees or rollers are applied on the plies to remove entrapped air. The bagged laminate is cured by a hot-press machine which can automatically adjust curing pressure, temperature and time. A schematic description of the vacuum-bag molding is shown in Fig. 2. Laminates manufactured under various curing conditions are then cut by a diamond coated cutting tool for making specimens. The specimens are tested with an Instron testing machine in accordance with the ASTM specifications for determining the mechanical properties of the laminates. The relations between laminate mechanical properties and curing parameters can then be established using the test results.

\section{RESULTS AND DISCUSSION}

Optimal curing parameters for laminates manufactured by the vacuum-bag molding with one temperature-time step in the cure cycle are first studied. In this case, $p=101.3 \mathrm{KN} / \mathrm{m}^{2}$ (one atmospheric pressure) and the optimal curing temperature $\theta$ and time $t$ are determined from test results via the forementioned multi-level optimization approach. For illustration purpose, the mechanical properties (longitudinal Young's modulus $E_{1}$ and tensile strength $X_{T}$, transverse Young's modulus $E_{2}$ and tensile strength $Y_{T}$, shear modulus $G_{12}$ and shear strength $R$ ) of the laminates cured at various temperatures and times are tabulated in Tables 1-3 for reference.

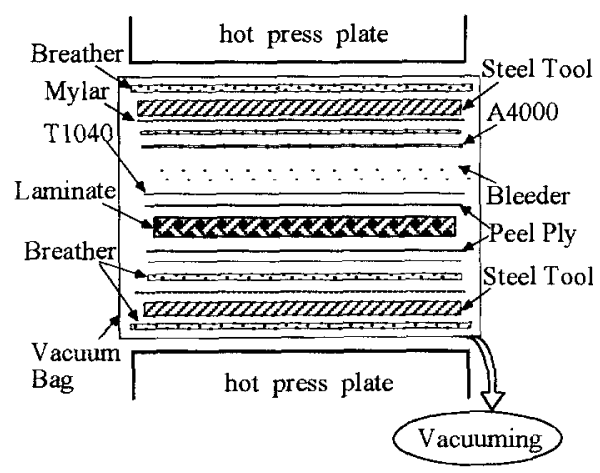

Fig. 2 Vacuum - bag molding

Table 1

Material properties of $\mathrm{Gr} / \mathrm{ep}$ laminates in fiber direction

\begin{tabular}{|c|c|c|c|c|c|}
\hline Time & ${ }^{\circ} \mathrm{C}$ & 120 & 140 & 160 & 180 \\
\hline \multirow{2}{*}{$45 \mathrm{~min}}$. & $\mathrm{X}_{\mathrm{T}}(\mathrm{Mpa})$ & 1420.34 & 1639.35 & 1674.70 & 1572.24 \\
\hline & $\mathrm{E}_{1}$ (Gpa) & 81.49 & L & -84.58 & 81.96 \\
\hline \multirow{2}{*}{$1 \mathrm{hr}}$. & $X_{\mathrm{T}}(\mathrm{Mpa})$ & 1708.00 & 1685.40 & 1573.30 & 1509.80 \\
\hline & $\mathrm{E}_{1}(\mathrm{Gpa})$ & 91.02 & 88.03 & 87.15 & 86.66 \\
\hline \multirow{2}{*}{$1.5 \mathrm{hr}$. } & $\mathrm{X}_{\mathrm{T}}(\mathrm{Mpa})$ & 1667.90 & $\overrightarrow{1359.70}$ & $\overline{14} \overrightarrow{13} . \overline{40}$ & 1526.60 \\
\hline & $E_{1}(\mathrm{Gpa})$ & 86.58 & 79.85 & 81.28 & 82.30 \\
\hline \multirow{2}{*}{$2 \mathrm{hr}$. } & $\mathrm{X}_{\mathrm{T}}$ (Mpa) & 1686.90 & 1553.40 & 1494.10 & 1642.30 \\
\hline & $E_{1}(\mathrm{Gpa})$ & 88.12 & -83.48 & -81.70 & $\ldots$ \\
\hline
\end{tabular}


Table 2

Material properties of $\mathrm{Gr} / \mathrm{ep}$ laminates in transverse direction

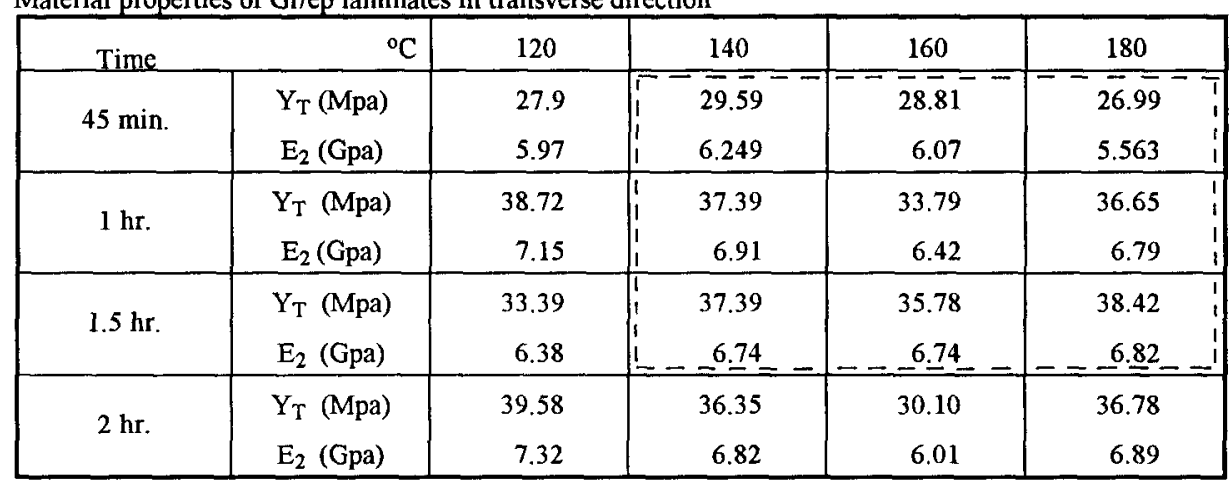

Table 3

Shear strength and modulus of $\mathrm{Gr} / \mathrm{ep}$ laminates

\begin{tabular}{|c|c|c|c|c|c|}
\hline Time & ${ }^{\circ} \mathrm{C}$ & 120 & 140 & 160 & 180 \\
\hline \multirow{2}{*}{$45 \mathrm{~min}}$. & R (Mpa) & 20.50 & $\overrightarrow{44.80}$ & $\overline{42.17}$ & $\overline{38.09}$ \\
\hline & $\mathrm{G}_{12}$ (Gpa) & 3.08 & 3.78 & 3.24 & 3.10 \\
\hline \multirow{2}{*}{$1 \mathrm{hr}}$. & $\mathrm{R}$ (Mpa) & 20.47 & 46.94 & 43.54 & 38.78 \\
\hline & $\mathrm{G}_{12}$ (Gpa) & 3.02 & 3.98 & 3.56 & 3.25 \\
\hline \multirow{2}{*}{$1.5 \mathrm{hr}$. } & R (Mpa) & 43.21 & 45.33 & 44.01 & 46.38 \\
\hline & $\mathrm{G}_{12}$ (Gpa) & 3.61 & 3.78 & 3.67 & 3.85 \\
\hline \multirow{2}{*}{$2 \mathrm{hr}}$. & $\mathrm{R} \quad$ (Mpa) & 46.44 & 44.73 & 38.21 & 45.92 \\
\hline & $\mathrm{G}_{12}$ (Gpa) & 4.04 & 3.78 & 3.32 & 3.57 \\
\hline
\end{tabular}

It is noted that in the above tables each material property was obtained by averaging the values of three specimens. Figs. 3-8 show the relations between mechanical properties and curing parameters, in which each contour gives the same value for the material property under consideration.

When the present multi-level optimization method is used, only the data of the regions unblocked by the dash lines in Tables 1-3 are needed for determining the optimal values of curing temperature and time for maximum material properties. As an example, in Table 1 only the first row and the first column are needed for determining the maximum values of longitudinal
Young's modulus $E_{I}$ and tensile strength $X_{T}$. Therefore, It is easy to realize that the present method can greatly reduce the number of specimens for determining the optimal curing parameters. In summary, the optimal curing parameters for maximum material properties obtained by the present method are given in Table 4 . It is noted that, as indicated in Table 4 , the optimal curing parameters may be different for different material parameters. For example, the optimal curing temperature and time are $\bar{\theta}=120^{\circ} \mathrm{C}$ and $\tilde{t}=$ $1.0 \mathrm{hr}$ for maximum longitudinal Young's Modulus $E_{1}$ while those for maximum transverse Young's modulus $E_{2}$ are $\tilde{\theta}=120^{\circ} \mathrm{C}$ and $\tilde{t}=2.0 \mathrm{hr}$ 


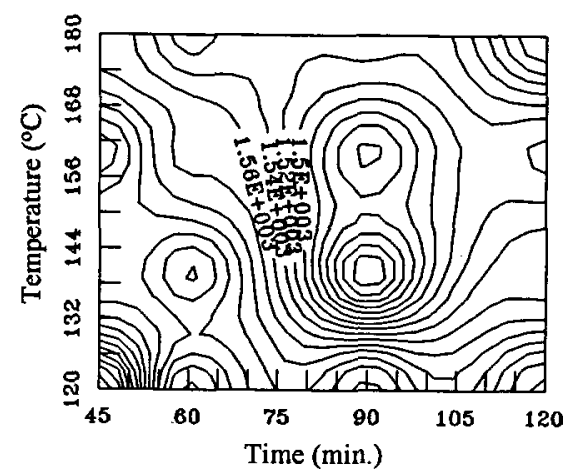

Fig. 3 Contours for tensile strength in fiber direction $\mathrm{X}_{\mathrm{T}}$

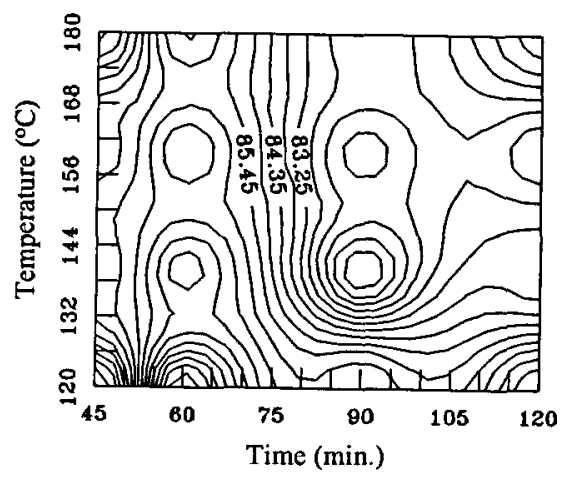

Fig. 4 Contours for longitudinal Young's Modulus $\mathrm{E}_{1}$

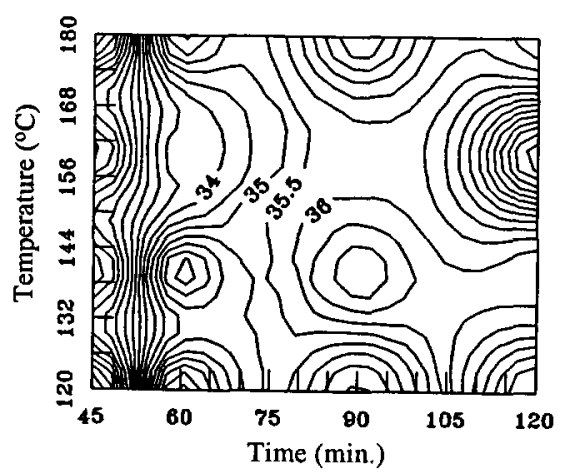

Fig. 5 Contours for tensile strength in transverse direction $\mathrm{X}_{\mathrm{T}}$

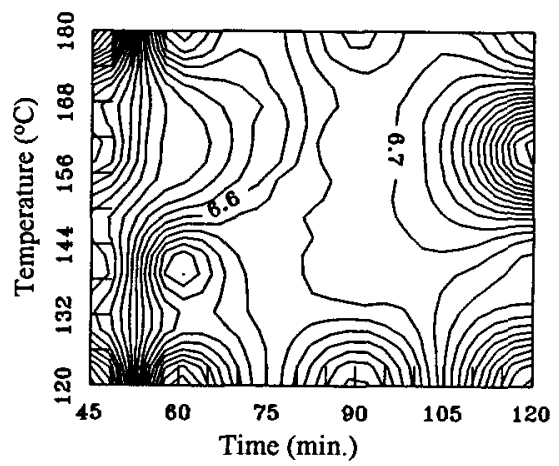

Fig. 6 Contours for transverse Young's Modulus $E_{2}$

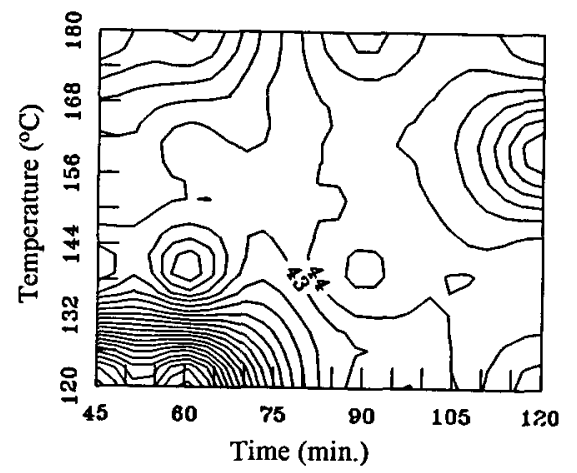

Fig. 7 Contours for shear strength $R$

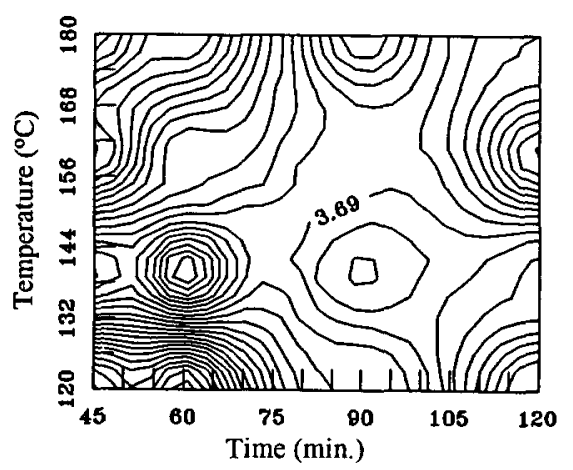

Fig. 8 Contours for shear Modulus $\mathrm{G}_{12}$ 
Table 4

Optimal curing parameters for one temperature-time step

\begin{tabular}{|c|c|c|c|}
\hline Material property & Magnitude & Temperature ( $\left.{ }^{\circ} \mathrm{C}\right)$ & Time (hr.) \\
\hline $\mathrm{X}_{\mathrm{T}}$ & $1708 \mathrm{Mpa}$ & 120 & 1.0 \\
\hline $\mathrm{E}_{1}$ & $91.02 \mathrm{Gpa}$ & 120 & 1.0 \\
\hline $\mathrm{YT}_{\mathrm{T}}$ & $39.58 \mathrm{Mpa}$ & 120 & 2.0 \\
\hline $\mathrm{E}_{2}$ & $7.32 \mathrm{Gpa}$ & 120 & 2.0 \\
\hline $\mathrm{R}$ & $46.44 \mathrm{Mpa}$ & 120 & 2.0 \\
\hline $\mathrm{G}_{12}$ & $4.04 \mathrm{Gpa}$ & 120 & 2.0 \\
\hline
\end{tabular}

Table 5

Material properties of $\mathrm{Gr} / \mathrm{ep}$ laminates cured by two pressure-temperature-time steps

\begin{tabular}{|cccccc|}
\hline \multicolumn{7}{c}{ Curing Parameter } \\
\hline$p_{1}$ & $\theta_{1}$ & $t_{1}$ & $p_{1}$ & $\theta_{1}$ & $t_{1}$ \\
\hline 101.3 & 80 & 50 & $2.07 \times 10^{3}$ & 120 & 80 \\
$\left(\mathrm{KN} / \mathrm{m}^{2}\right)$ & $\left({ }^{\circ} \mathrm{C}\right)$ & $(\mathrm{min})$ & $\left(\mathrm{KN} / \mathrm{m}^{2}\right)$ & $\left({ }^{\circ} \mathrm{C}\right)$ & $(\mathrm{min})$ \\
\hline & & \multicolumn{2}{c}{ Material Property } & & \\
\hline $\mathrm{X}_{\mathrm{T}}$ & $\mathrm{E}_{1}$ & $\mathrm{Y}_{\mathrm{T}}$ & $\mathrm{E}_{2}$ & $\mathrm{R}$ & $\mathrm{G}_{12}$ \\
\hline 2194 & 143. & 41. & 9.8 & 78.8 & 4.7 \\
$(\mathrm{Mpa})$ & $(\mathrm{Gpa})$ & $(\mathrm{Mpa})$ & $(\mathrm{Gpa})$ & $(\mathrm{Mpa})$ & $(\mathrm{Gpa})$ \\
\hline
\end{tabular}

It is worthy to point out that the actual optimal curing parameters for yielding maximum shear strength $(\mathrm{R}=46.94 \mathrm{Gpa})$ are $\theta=140^{\circ} \mathrm{C}$ and $t=$ $1.0 \mathrm{hr}$. which are different from those $(\tilde{R}=46.44$ Gpa , $\tilde{\theta}=120^{\circ} \mathrm{C}$ and $\tilde{t}=2.0 \mathrm{hr}$.) predicted by the present method. However, the difference between the actual and predicted maximum shear strengths is so small that the present method is found acceptable. In a similar way, the present optimization method has also been applied to the case of two $p-\theta-t$ steps. As an example, the optimal curing parameters (pressure, temperature, and time) for achieving maximum longitudinal Young's modulus $\mathrm{E}_{1}$ are listed together with the corresponding material properties in Table 5 . Comparing the results given in Tables 4 and 5 , it is noted that the use of two $p-\theta-t$ steps can yield laminates with better material properties but requires longer curing time.

\section{CONCLUSION}

A multi-level optimization method has been developed for determining the optimal curing parameters for composite laminates with maximum material properties. The method was applied to the determination of optimal curing parameters for $Q-$ $1115 \mathrm{Gr} / \mathrm{ep}$ laminates. The effectiveness of the present method has been demonstrated by means of a number of examples. The use of the present method can significantly reduce the number of specimens required in the determination of optimal curing parameters when compared to the conventional approach. It has also been shown that 
among the one and two $p-\theta-t$ steps curing processes, the two steps process can, in general, yield laminates with better material properties. The present method is applicable for more general cases even though the effects of laminate and mold thicknesses on the optimal curing parameters have not been considered in the illustrative examples.

\section{REFERENCES}

1. M. M. Schwartz, Composite Materials Handbook, McGraw-Hill Book Co. New York, 1983.

2. G. Lubin (Ed.), Handbook of Composites, van Nostrand Reinhold Co., London, 1982.

3. R. B. Prime, Polymer 13(1972) 455.

4. W. Fisch, W. Hofmann and J. Koskikallio, J. Appl. Chem., 6(1956) 429.

5. H. Waddill, U. S. Patent 3943104 (1976)

6. N. B. Godfrey, U. S. Patent 3785997 (1974)

7. T. Y. Kam and M. D. Lai, Comput. and Struct., 31(1989) 197.

8. T. Y. Kam, J. Eng. Optimization, 19(1992)81.

9. G. N. Vanderplaats, Numerical Optimization Techniques for Engineering Design : With Applications, McGraw-Hill, Inc., New York, 1984. 